Article

\title{
Evaluation of AquaCrop Model for Foxtail Millet (Setaria italica) Growth and Water Use with Plastic Film Mulching and No Mulching under Different Weather Conditions
}

\author{
Da-Xin Guo ${ }^{1,2}$, Chao-Fei Chen ${ }^{1,2}$, Ping-Yi Guo ${ }^{3}$, Xiang-Yang Yuan ${ }^{3}$, Xu-Guang Xing ${ }^{1,2}$ and \\ Xiao-Yi Ma ${ }^{1,2, *}$ \\ 1 College of Water Resources and Architectural Engineering, Northwest A\&F University, Yangling 712100, \\ China; guodaxin@nwafu.edu.cn (D.-X.G.); chenchaofei@nwafu.edu.cn (C.-F.C.); xingxg86@163.com (X.-G.X.) \\ 2 Key Laboratory of Agricultural Soil and Water Engineering in Arid and Semiarid Areas, Ministry of \\ Education, Northwest A\&F University, Yangling 712100, China \\ 3 College of Agronomy, Shanxi Agricultural University, Taigu 030800, China; pyguo@sxau.edu.cn (P.-Y.G.); \\ yuanxiangyang200@163.com (X.-Y.Y.) \\ * Correspondence: xma@nwafu.edu.cn; Tel.: +86-29-8708-2860
}

Received: 3 April 2018; Accepted: 20 June 2018; Published: 23 June 2018

\begin{abstract}
The water-driven AquaCrop model is used extensively for simulating crop growth and water use. A three-year field experiment (2015-2017) of foxtail millet (Setaria italica) that was grown using plastic film mulching (PM) and no mulching (NM) was conducted in a rain-fed region of China to simulate canopy cover (CC), biomass, soil water content (SWC), yield, evapotranspiration (ETc), and water use efficiency (WUE). The year 2015 was much drier and warmer than the two other years. The model was calibrated using field data from 2016 and validated using the data from 2015 and 2017. Simulations of CC, biomass, and yield achieved favorable performance for both PM and NM in all years, as indicated by the high determination coefficient $\left(R^{2}\right)$, model efficiency (EF), small root mean square error (RMSE), normalized root mean square error (NRMSE), and deviations $<10 \%$. Simulations of SWC, ETc, and WUE gave acceptable results for both PM and NM in the normal year (2017). However, low $\mathrm{R}^{2}$ and EF, and large NRMSE, RMSE, and deviations were observed in the predictions of PM and NM for SWC, ETc, and WUE in the dry year (2015) with a severe drought stress, indicating that the model performed unsatisfactorily under severe drought stress condition that was caused by the adverse weather. In addition, the simulation performance of NM was more favorable than that of PM for most crop growth and water use indexes under no drought stress condition.
\end{abstract}

Keywords: AquaCrop; foxtail millet; mulching; canopy cover; biomass; water use efficiency; rain fed

\section{Introduction}

Water resource scarcity is the most limiting factor for agricultural production in many parts of the world. Mulch has been used throughout the world to increase crop yields and water use efficiency, especially in areas where water resources are scarce. Recently, many biodegradable materials have been used in mulching with great effects, leading many to conclude that mulching will have considerable applications in the future of agriculture [1]. Plastic film mulching (PM) is currently the principal method that is used for mulch. Many studies have reported that PM significantly improves growth, yield, and water use efficiency (WUE) for many crops, such as wheat [2], maize [3], cotton [4], and sweet pepper [5] in both rain-fed and irrigated areas.

The objective of using a crop model is to study the impact of agronomic technology, climate, and soil on crop development and growth, yield, and water productivity. The water-driven crop 
model AquaCrop was developed by the Food and Agriculture Organization of the United Nations (FAO) [6]. It has a user-friendly interface, provides mulches option, and requires less input data than other crop models [5,7]. As a model that is based on crop responses to water, AquaCrop provides better simulation results in crop WUE and soil water content (SWC) than other crop models in the study areas where water is a crucial factor determining yield $[8,9]$. Many studies have indicated that AquaCrop achieved precise modeling results for canopy cover (CC), biomass, yield, and SWC for maize [10], wheat [11] and soybeans [12]. Bello and Walker [13] tested the AquaCrop model for simulating the CC, biomass, yield, and cumulative evapotranspiration (ETc) of pearl millet under different irrigations and noted good agreement between the simulated and observed data. Few studies have applied the AquaCrop model under PM condition. Malik et al. [14] tested the applicability of AquaCrop on predicting sugar beet CC, biomass, and root yield under different film mulching and irrigation regimes. Ran et al. [15] studied the performance of two models (AquaCrop and SIMDualKc) for crop ETc partitioning of maize under PM conditions.

Extreme meteorological events will occur frequently in the future under climate change scenarios [16]. Thus, the study and projection of agricultural production and water consumption under climate change in arid regions are vital $[17,18]$. Cosic et al. [5] reported that PM played a significant role in mitigating adverse effects on sweet pepper yields, owing to the extreme weather. Bird et al. [19] found similar results in the simulation of tomato using AquaCrop. Furthermore, several researchers have noted that crop model calibration is essentially site-specific and simulation performance should be assessed using different field management, climate, crop, and soil to constantly provide suggestions for improving the accuracy and applicability of models [10,20]. Therefore, calibrating crop models for more cultivars with and without PM are necessary, and model performance should be evaluated in simulating crop growth and water use under different weather conditions.

Millets, including foxtail millet (Setaria italica), pearl millet (pennisetum glaucum), and finger millet (Eleusine coracana), are widely known as rain-fed crops. They are main food and fodder crop worldwide, particularly in Asia and Africa [13]. China is the primary consumer and producer of foxtail millet, with a total sowing area of over 150,000 ha [21]. Because the hybrid foxtail millet "zhangzagu" has many favorable characteristics, such as high yield, drought tolerance, and nutritional value, it has been cultivated over a large area of northern China where the majority of land is rain-fed [22]. PM is the primary cultivation method for foxtail millet in China [21]. However, few studies have simulated millets growth using crop models at present [23].

The main objective of this study was to parametrize and to evaluate the AquaCrop model by using it to simulate growth, water use, and soil water content of foxtail millet grown with and without filming mulching under different weather conditions, to determine whether the model can be used in agricultural production and water management in the north of China.

\section{Material and Methods}

\subsection{Research Area}

The experiments were conducted at an innovative agriculture garden in Taigu $\left(37^{\circ} 23^{\prime} \mathrm{N}, 112^{\circ} 29^{\prime} \mathrm{E}\right.$ at $780 \mathrm{~m}$ elevation), Shanxi Province, northern China. The experimental region has a typical warm and semi-arid climate, where the mean annual precipitation was $420 \mathrm{~mm}$ and the mean frost-free days ranges from 160 to 190 days; the annual accumulated temperature $\left(>0{ }^{\circ} \mathrm{C}\right)$ is $3500{ }^{\circ} \mathrm{C}$.

\subsection{Climate Data}

The climate data during the growing period of foxtail millet were obtained from the National Meteorological Information Center of the China Meteorological Administration (http://cdc.cma. gov.cn/), which included daily precipitation, daily air maximum, and minimum temperatures (Figure 1). Daily reference evapotranspiration (ETo) (Figure 1) was calculated by the FAO ETo calculator (http://www.fao.org/nr/water/eto.html). 


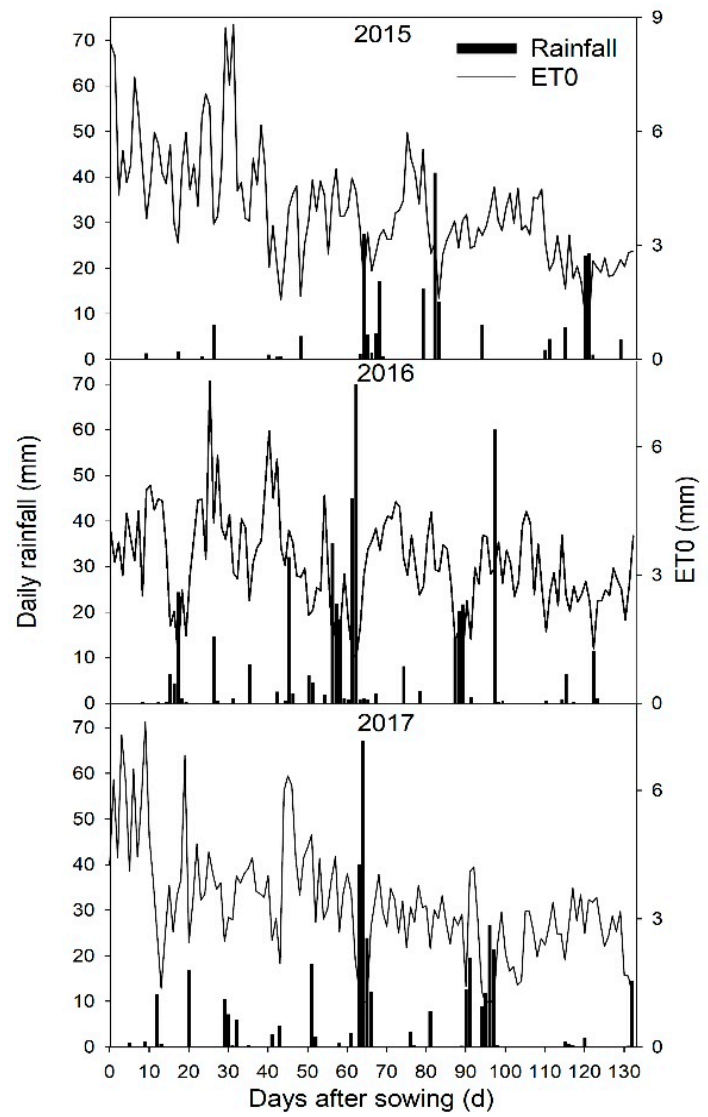

(a)

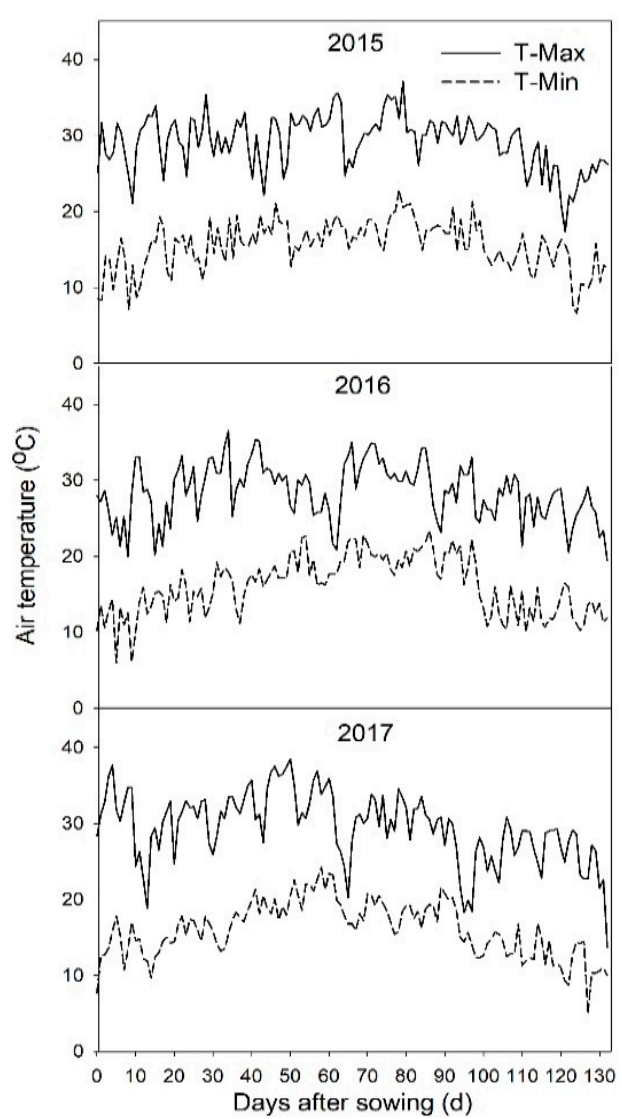

(b)

Figure 1. (a) Daily rainfall and reference evapotranspiration (ETo) during the study period in 2015, 2016, and 2017; and, (b) Daily temperature during the study period in 2015, 2016, and 2017.

The type of rainfall year was determined by using the criteria proposed by Tao et al. [24], shown as following: Wet year: $\mathrm{P}_{\mathrm{i}}>\mathrm{P}+0.33 \delta$; dry year: $\mathrm{P}_{\mathrm{i}}<\mathrm{P}-0.33 \delta$, where $\mathrm{P}_{\mathrm{i}}$ is the rainfall for year $(\mathrm{mm})$, $P$ is the multi-year (1960-2014) average rainfall $(\mathrm{mm})$, and $\delta$ is the mean of the squared deviations of each year's total rainfall from the multi-year average. Because the growing season of foxtail millet runs from May to September, yearly $\mathrm{P}_{\mathrm{i}}$ values were calculated in terms of the precipitation falling during this period. According to the criteria, 2016 was a wet year (total precipitation: $477 \mathrm{~mm}$ ), 2017 was a normal year (total precipitation: $365 \mathrm{~mm}$ ), and 2015 was a dry year (total precipitation: $256 \mathrm{~mm}$ ). Moreover, the daily average temperature during the study period in 2015 was higher than that in 2016 and 2017 by 0.5 and $0.3^{\circ} \mathrm{C}$, respectively (Figure 1). Especially, the daily average temperature in June 2015 was 1.1 and $0.6{ }^{\circ} \mathrm{C}$ higher than the daily average temperature in June 2016 and June 2017, respectively.

\subsection{Filed Management and Crop Data}

This study employed two treatments: (1) Plastic film mulching (PM) and (2) no mulching (NM). Three years $(2015,2016$, and 2017) of field experiments were conducted using a completely randomized block design with five replications. Each plot was $14 \mathrm{~m}$ long and $2 \mathrm{~m}$ wide with row spacing of $46 \mathrm{~cm}$. Foxtail millet seeds were sown on 12 May 2015, 19 May 2016, and 25 May 2017. The plant density was 340,000 plants ha ${ }^{-1}$, mulched with flat soil dibbling, and covered by a $0.01 \mathrm{~mm}$ thick transparent polyethylene plastic film. Soil cover by mulches was about $50 \%$. On 9 July 2015, all of the plots were irrigated with $45 \mathrm{~mm}$ of water due to the severe drought. Manual weeding was adopted in the experimental field. The weed management was excellent in 2015 and 2016 crop season; weeds cover was about 1\%. The weed management was good in 2017 crop season; weeds cover was about 10\%. 
The cultivar of hybrid foxtail millet was "zhangzagu 10". Each growth stage of foxtail millet was recorded over three years (Table 1). The growth period of PM treatment and NM treatment in 2015 was three days and one day shorter than those in 2016, respectively. The difference between the length of the growth period of PM and NM in 2017 and those in 2016 is very small.

Canopy cover (CC) was calculated using the empirical relationship between this value and the leaf area index (LAI). LAI was measured every 20 days after sowing using a leaf area meter (CI-230, CID Inc., Camas, WA, USA) on three randomly selected millet plants in each plot. LAI was calculated by dividing the total leaf area by the average ground area per plant. Canopy cover was calculated using Equation (1), as reported in Araya et al. [25]:

$$
\mathrm{CC}=1-\exp ^{(-0.65 \mathrm{LAI})}
$$

Aboveground biomass was measured every 20 days after sowing. To obtain this, three millet plants were randomly selected from each plot and dried in an oven for $48 \mathrm{~h}$ at $105^{\circ} \mathrm{C}$. Three areas of about $2 \mathrm{~m}^{2}$ (four rows of wide, $1 \mathrm{~m}$ long) were randomly harvested from each plot once the millet reached maturity. The ear number, ear grain weight, and 1000-grain weight of millet were measured to calculate the grain yield. Crop WUE was calculated, as follows:

$$
\mathrm{WUE}=\frac{\mathrm{Y}}{\mathrm{ETC}}
$$

where $\mathrm{Y}$ is grain yield $\left(\mathrm{kg} \cdot \mathrm{ha}^{-1}\right)$ of millet. ETc $(\mathrm{mm})$ was calculated, as follows:

$$
\mathrm{ETC}=\mathrm{P}+\mathrm{I}-\Delta \mathrm{SW}-\mathrm{R}-\mathrm{D}
$$

where $\mathrm{P}$ is precipitation $(\mathrm{mm}), \mathrm{I}$ is irrigation $(\mathrm{mm}), \mathrm{D}$ is deep percolation $(\mathrm{mm}), \mathrm{R}$ is runoff $(\mathrm{mm})$, and $\triangle \mathrm{SW}$ is change of SWC in the $1.6 \mathrm{~m}$ soil profile between the planting and harvesting periods. Deep percolation and runoff were assumed as zero based on the experimental condition. 
Table 1. Days to attainting various growth stages of foxtail millet for plastic film mulching (PM) and no mulching (NM) in 2015, 2016 , and 2017.

\begin{tabular}{|c|c|c|c|c|c|c|c|}
\hline \multicolumn{8}{|c|}{ Days to Growth Stages } \\
\hline Years & Treatments & Seedling (Days) & Jointing (Days) & Booting (Days) & Heading (Days) & Maturity (Days) & Days to Harvest (Days \\
\hline \multirow{2}{*}{2015} & $\mathrm{PM}$ & $\begin{array}{l}\text { 13th May-2nd June } \\
\text { (19 days) }\end{array}$ & $\begin{array}{l}\text { 2nd June-19th June } \\
\text { (17 days) }\end{array}$ & $\begin{array}{l}\text { 19th June-14th July } \\
\text { (25 days) }\end{array}$ & $\begin{array}{l}\text { 14th July-30th July } \\
\text { (16 days) }\end{array}$ & $\begin{array}{l}\text { 30th July-11th September } \\
\text { (44 days) }\end{array}$ & 121 \\
\hline & $\mathrm{NM}$ & $\begin{array}{l}\text { 13th May-5th June } \\
\text { (22 days) }\end{array}$ & $\begin{array}{l}\text { 4th June-25th June } \\
\text { (20 days) }\end{array}$ & $\begin{array}{l}\text { 25th June-21th July } \\
\text { (26 days) }\end{array}$ & $\begin{array}{l}\text { 21th July-7th August } \\
\text { (17 days) }\end{array}$ & $\begin{array}{l}\text { 7th August-19th September } \\
\text { (44 days) }\end{array}$ & 129 \\
\hline \multirow{2}{*}{2016} & $\mathrm{PM}$ & $\begin{array}{l}\text { 20th May-9th June } \\
\text { (20 days) }\end{array}$ & $\begin{array}{l}\text { 9th June-28th June } \\
\text { (19 days) }\end{array}$ & $\begin{array}{l}\text { 28th June-23th July } \\
\text { (25 days) }\end{array}$ & $\begin{array}{l}\text { 23th July-8th August } \\
\text { (16 days) }\end{array}$ & $\begin{array}{c}\text { 8th August-21th September } \\
\text { (44 days) }\end{array}$ & 124 \\
\hline & $\mathrm{NM}$ & $\begin{array}{l}\text { 20th May-11th June } \\
\text { (22 days) }\end{array}$ & $\begin{array}{l}\text { 11th June-2nd July } \\
\text { (21 days) }\end{array}$ & $\begin{array}{l}\text { 2nd July-23th July } \\
\text { (26 days) }\end{array}$ & $\begin{array}{l}\text { 23th July-9th August } \\
\text { (17 days) }\end{array}$ & $\begin{array}{l}\text { 9th August-27th September } \\
\text { (44 days) }\end{array}$ & 130 \\
\hline \multirow{2}{*}{2017} & $\mathrm{PM}$ & $\begin{array}{l}\text { 25th May-14th June } \\
\text { (19 days) }\end{array}$ & $\begin{array}{l}\text { 14th June-3rd June } \\
\text { (19 days) }\end{array}$ & $\begin{array}{l}\text { 3rd June-28th July } \\
\text { (25 days) }\end{array}$ & $\begin{array}{l}\text { 28th July-13th August } \\
\text { (16 days) }\end{array}$ & $\begin{array}{l}\text { 13th August-25th September } \\
\text { (44 days) }\end{array}$ & 123 \\
\hline & NM & $\begin{array}{l}\text { 25th May-17th June } \\
\text { (22 days) }\end{array}$ & $\begin{array}{l}\text { 17th June-8th July } \\
\text { (21 days) }\end{array}$ & $\begin{array}{l}\text { 8th July-4th July } \\
\text { (26 days) }\end{array}$ & $\begin{array}{l}\text { 4th July-20th August } \\
\text { (17 days) }\end{array}$ & $\begin{array}{l}\text { 20th August-2nd October } \\
\text { (44 days) }\end{array}$ & 130 \\
\hline
\end{tabular}




\subsection{Soil Data}

The organic matter, available nitrogen, available phosphorus, and available potassium in the plow layer of the soil $(0-30 \mathrm{~cm})$ were measured with a soil nutrient meter (TPY-6 TOP Inc., Hangzhou, Zhejiang, China), and their contents were $23.79 \mathrm{~g} \cdot \mathrm{kg}^{-1}, 77.83 \mathrm{mg} \cdot \mathrm{kg}^{-1}, 6.81 \mathrm{mg} \cdot \mathrm{kg}^{-1}$, and $200.35 \mathrm{mg} \cdot \mathrm{kg}^{-1}$, respectively. The average $\mathrm{pH}$ of the soil was 8.16 . The soil textural class was determined through the hydrometer method using USDA soil texture classification [26]. Table 2 lists the soil characteristics of the experimental field, parts of which were obtained from Liu and Zhang [27]. The Soil Water Characteristics Hydraulic Properties Calculator (http:/ / hydrolab.arsusda. gov/soilwater/Index.htm) was used to calculate the soil water content at saturation (SAT), field capacity (FC), permanent wilting point (PWP), and saturated hydraulic conductivity (Ksat). The soil water table depth of Taigu is chronically kept five meters below soil surface [28]. Therefore, the groundwater table of the experimental field was set to $5 \mathrm{~m}$ below the soil surface. The capillary rise function was calibrated using the default settings for the selected soil texture and $\mathrm{K}_{\text {sat }}$. Due to the fact that the height of field soil bunds was $0.2 \mathrm{~m}$, the surface run-off curve number $(\mathrm{CN})$ was not applicable [29]. Readily evaporable water (REW) was set to the default value.

Table 2. Soil characteristics of the experimental field at Taigu.

\begin{tabular}{|c|c|c|c|c|c|c|}
\hline Depth (cm) & Texture & $\begin{array}{l}\text { Bulk Density } \\
\left(\mathrm{g} \cdot \mathrm{cm}^{-3}\right)\end{array}$ & $\mathrm{SAT}\left(\mathrm{mm} \cdot \mathrm{m}^{-1}\right)$ & $\mathrm{FC}\left(\mathrm{mm} \cdot \mathrm{m}^{-1}\right)$ & $\operatorname{PWP}\left(\mathrm{mm} \cdot \mathrm{m}^{-1}\right)$ & Ksat $\left(\mathrm{mm} \cdot \mathrm{day}^{-1}\right)$ \\
\hline $0-20$ & Sandy clay loam & 1.39 & 430 & 310 & 135 & 450 \\
\hline $20-40$ & Clay loam & 1.45 & 410 & 345 & 150 & 225 \\
\hline $40-60$ & Clay loam & 1.51 & 460 & 360 & 155 & 210 \\
\hline $60-80$ & Clay loam & 1.57 & 480 & 395 & 164 & 205 \\
\hline 80-100 & Sandy clay & 1.59 & 460 & 390 & 164 & 140 \\
\hline $100-130$ & Sandy clay & 1.62 & 460 & 385 & 159 & 130 \\
\hline $130-160$ & Sandy clay & 1.63 & 463 & 383 & 157 & 130 \\
\hline
\end{tabular}

SAT: Water content at saturation; FC: Field capacity; PWP: Permanent wilting point; Ksat: Saturated hydraulic conductivity.

The soil water content was measured using the standard gravimetric method every 15 days after sowing. Samples were obtained by means of a drill with two replicates in each plot, from seven layers: 0-20, 20-40, 40-60, 60-80, 80-100, 100-130, and 130-160 cm.

\subsection{Model Calibration and Validation}

Farahani et al. [30] showed that calibration is adjusting some model parameters to make the model match the measured data at the specific location. The AquaCrop required some necessary input data to define the environment in which the crop will develop, including weather, crop, field management, soil, and initial condition data. All of these data were entered into corresponding modules before running the simulation. The input data of the initial conditions in AquaCrop was measured at the start of each experiment. The measured crop data from the field was used as input data for crop development parameters, including plant density, initial canopy cover (CCo), maximum canopy cover (CCx), maximum and minimum effective rooting depth, day to emergence, day to CCx, day to maturity, and day to flowering. Whereas, the remaining crop parameters, such as canopy growth and decline coefficients, were estimated by the model after the input data were entered. Then, these parameters were continuously adjusted to match the measured data for canopy cover, biomass, and yield.

The model was calibrated with measured data from 2016 as the highest yield and biomass were measured in 2016. From the observed data, it can be found that some measured crop data of PM obviously differed from those of NM, such as the growth stage of foxtail millet (Table 1), initial and maximum canopy cover, and the harvest index. Therefore, it was difficult to adjust the measured crop data that were distinctly different between PM and NM treatments to the input data of one set of crop parameters. So, based on the method from the studies which used AquaCrop to simulate crop growth under PM and NM conditions [14,31], we established two sets of crop parameters and corresponding mulching parameters: PM and NM. In the module of field management, AquaCrop provided the 
option of mulches, where the user could specify the degree of soil cover and the type of surface mulches. Depending on the type of mulches and the fraction of the soil surface covered, the reduction in soil evaporation might be more or less substantial [32]. At the present study, plastic mulches completely reduced the evaporation of water from the soil surface $(100 \%)$. The calibration process described by Steduto et al. [6] was followed for the model calibration. The reference harvest index (HIo) was adjusted to simulate the measured yield in the experimental field. The field management was set at field conditions of non-limiting soil salinity stress and soil fertility stress. A trial-and-error method was adopted to obtain the minimum error values between the simulated and measured data in calibration.

The model was validated through comparing the simulated data with the measured data, as obtained from 2015 and 2017. The indexes evaluated for goodness-of-fit of the model were CC, aboveground biomass, SWC, yield, ETc, and WUE. The AquaCrop version was 6.0.

\subsection{Model Performance Assessment}

Goodness-of-fit for the calibration and validation of the model was carried out with four statistical indicators: The coefficient of determination $\left(\mathrm{R}^{2}\right)$, root mean square error (RMSE), normalized root mean square error (NRMSE), and model efficiency (EF), which were calculated, as follows:

$$
R^{2}=\left[\frac{\sum\left(M_{i}-\bar{M}\right)\left(S_{i}-\bar{S}\right)}{\sqrt{\sum\left(M_{i}-\bar{M}\right)^{2}\left(S_{i}-\bar{S}\right)^{2}}}\right]^{2}
$$

where $S_{i}$ and $M_{i}$-simulated and measured values, and $\bar{S}$ and $\bar{M}$-average values of simulated and measured data. That $R^{2}$ value gets close to 1 indicated favorable agreement between the simulated and measured values. If the $\mathrm{R}^{2}$ value $>0.5$, it indicated that the simulation results were considered acceptable in watershed simulations [33].

$$
\operatorname{RMSE}=\sqrt{\frac{\sum\left(\mathrm{S}_{\mathrm{i}}-\mathrm{M}_{\mathrm{i}}\right)^{2}}{\mathrm{n}}}
$$

where $\mathrm{n}$ is the total number of observations. As the RMSE value approaches 0 , the deviation decreases between the simulated and measured values.

$$
\mathrm{NRMSE}=\sqrt{\frac{\sum\left(\mathrm{S}_{\mathrm{i}}-\mathrm{M}_{\mathrm{i}}\right)^{2}}{\mathrm{n}} \times \frac{100}{\overline{\mathrm{M}}}}
$$

The simulation was labeled (1) excellent, (2) good, (3) fair, or (4) poor for NRMSE values smaller than $10 \%$, between $10 \%$ and $20 \%$, between $20 \%$ and $30 \%$, or $>30 \%$, respectively [34].

$$
\mathrm{EF}=1-\frac{\sum_{i=1}^{n}\left(\mathrm{M}_{\mathrm{i}}-\mathrm{S}_{\mathrm{i}}\right)^{2}}{\sum_{i=1}^{n}\left(\mathrm{M}_{\mathrm{i}}-\overline{\mathrm{M}}\right)^{2}}
$$

The EF value ranged from 1 to negative infinity with a value of 1 corresponding to a perfect fit.

The data analysis of significant difference used statistics software Statistical Product and Service Solutions (SPSS) (LSD, $p=0.05$ ).

\section{Results}

\subsection{Model Calibration}

The calibrated and used crop and mulching parameters in the AquaCrop model are shown in Table 3. In addition to the crop parameters that were obtained from the measured data, the calibrated crop parameters for PM treatment, which displayed the length of different crop growth stages, were observed shorter than that for NM treatment i.e., days from sowing to start senescence, days from 
sowing to maximum rooting depth, and length of the flowering season. Three soil water stress coefficients describing the sensitivity of plant to soil water stress were chosen as 'moderately tolerant to water stress', including the soil water stress coefficient for canopy expansion, stomatal closure, and canopy senescence. The specific values of these parameters are shown in Table 3.

Table 3. Crop and mulching parameters used in AquaCrop to simulate foxtail millet under plastic film mulching (PM) and no mulching (NM) conditions.

\begin{tabular}{|c|c|c|c|c|}
\hline Descriptions & PM & NM & Units & Determination \\
\hline Base temperature & 7 & 7 & ${ }^{\circ} \mathrm{C}$ & $\mathrm{L}$ \\
\hline Upper temperature & 31 & 31 & ${ }^{\circ} \mathrm{C}$ & $\mathrm{L}$ \\
\hline $\begin{array}{l}\text { Soil water depletion factor for canopy expansion } \\
\text { (p-exp)-Lower threshold }\end{array}$ & 0.60 & 0.60 & - & $\mathrm{C}$ \\
\hline $\begin{array}{l}\text { Soil water depletion factor for canopy expansion } \\
\text { (p-exp)-Upper threshold }\end{array}$ & 0.25 & 0.25 & - & $\mathrm{C}$ \\
\hline $\begin{array}{l}\text { Shape factor for water stress coefficient for canopy expansion } \\
\qquad(0.0=\text { straight line })\end{array}$ & 3.0 & 3.0 & - & $\mathrm{D}$ \\
\hline $\begin{array}{l}\text { Soil water depletion fraction for stomatal control } \\
\text { (p-sto)_Upper threshold }\end{array}$ & 0.65 & 0.65 & - & $\mathrm{C}$ \\
\hline $\begin{array}{l}\text { Shape factor for water stress coefficient for stomatal control } \\
\qquad(0.0=\text { straight line })\end{array}$ & 3.0 & 3.0 & - & $\mathrm{D}$ \\
\hline $\begin{array}{l}\text { Soil water depletion factor for canopy senescence } \\
\text { (p-sen)_-Upper threshold }\end{array}$ & 0.65 & 0.65 & - & $\mathrm{C}$ \\
\hline $\begin{array}{l}\text { Shape factor for water stress coefficient for canopy senescence } \\
\qquad(0.0=\text { straight line })\end{array}$ & 3.0 & 3.0 & - & $\mathrm{D}$ \\
\hline $\begin{array}{l}\text { Vol\% for Anaerobiotic point (saturation at which deficient } \\
\text { aeration occurs) }\end{array}$ & 5 & 5 & $\%$ & $\mathrm{D}$ \\
\hline $\begin{array}{c}\text { Crop coefficient when canopy is complete but prior to } \\
\text { senescence }\left(\mathrm{K}_{\left.\mathrm{Cr}_{\mathrm{Tr}, \mathrm{x}}\right)}\right.\end{array}$ & 0.98 & 0.98 & - & $\mathrm{C}$ \\
\hline Initial canopy cover $(\mathrm{CCo})$ & 0.51 & 0.41 & $\%$ & M \\
\hline Maximum green canopy cover (CCx) & 98 & 95 & $\%$ & M \\
\hline Canopy decline coefficient (CDC) & 7.5 & 9.3 & $\%$ day $^{-1}$ & $\mathrm{C}$ \\
\hline Canopy growth coefficient (CGC) & 14.4 & 14.5 & $\%$ day $^{-1}$ & $\mathrm{C}$ \\
\hline Days from sowing to emergency & 11 & 15 & days & M \\
\hline Days from sowing to maximum CC & 65 & 70 & days & M \\
\hline Days from sowing to start senescence & 111 & 112 & days & $\mathrm{C}$ \\
\hline Days from sowing to maturity & 124 & 130 & days & M \\
\hline Days from sowing to maximum rooting depth & 66 & 71 & days & $\mathrm{C}$ \\
\hline Length of the flowering season & 15 & 16 & days & $\mathrm{C}$ \\
\hline Duration of harvest index building up & 58 & 58 & days & $\mathrm{C}$ \\
\hline Days from sowing to flowering & 66 & 72 & days & M \\
\hline Maximum effective rooting depth & 1.65 & 1.45 & $\mathrm{~m}$ & M \\
\hline Minimum effective rooting depth & 0.3 & 0.3 & $\mathrm{~m}$ & M \\
\hline Maximum root water extraction in top quarter of root zone & 0.048 & 0.048 & $\mathrm{~m}^{3} \cdot \mathrm{m}^{-3}$ soil day ${ }^{-1}$ & $\mathrm{C}$ \\
\hline Maximum root water extraction in bottom quarter of root zone & 0.008 & 0.008 & $\mathrm{~m}^{3} \cdot \mathrm{m}^{-3}$ soil day ${ }^{-1}$ & $\mathrm{C}$ \\
\hline Water productivity & 23.8 & 22.6 & $\mathrm{~g} \cdot \mathrm{m}^{-2}$ & $\mathrm{C}$ \\
\hline Reference harvest index (HIo) & 49 & 47 & $\%$ & $\mathrm{C}$ \\
\hline Reduction of evaporation by mulches during the growing season & 50 & 0 & $\%$ & $\mathrm{C}$ \\
\hline
\end{tabular}

C: Calibrated; M: Measured; D: Default; L: Literature.

The calibration results indicated that the model was generally able to simulate CC development very well for both PM and NM in 2016 (Figure 2). Although slight underestimations of CC were demonstrated in the early and late growth seasons, strong agreement was exhibited between the measured and simulated data for both PM and NM, as indicated by $\mathrm{R}^{2}$ ranging from 0.98 to 0.99 , EF ranging from 0.96 to 0.97 , RMSE ranging from 5.9 to 6.8 , and NRMSE ranging from $8.9 \%$ to $9.5 \%$, respectively. Besides, the results of NM were observed to have lower RMSE and NRMSE and higher EF when compared with the results of PM. 

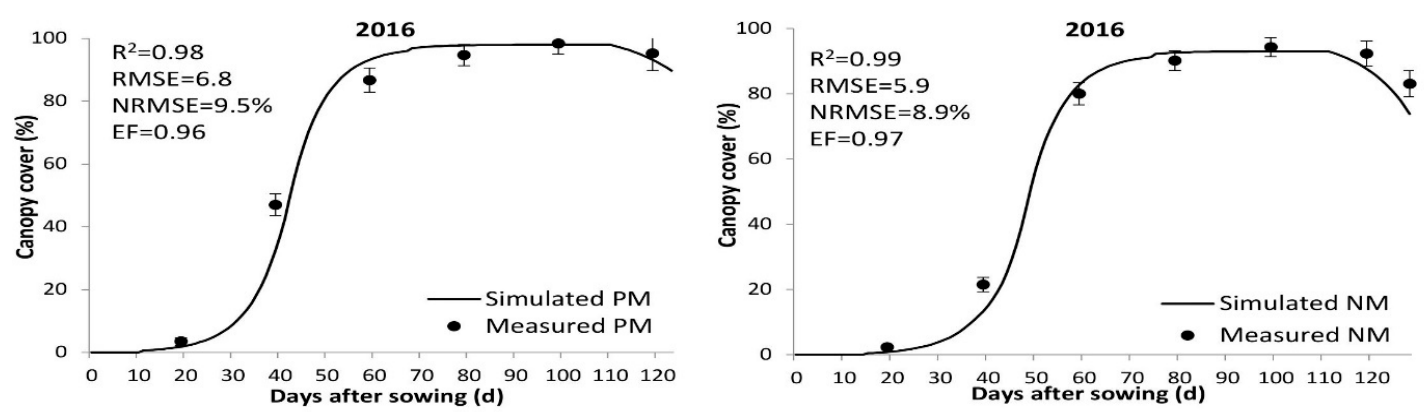

(a)
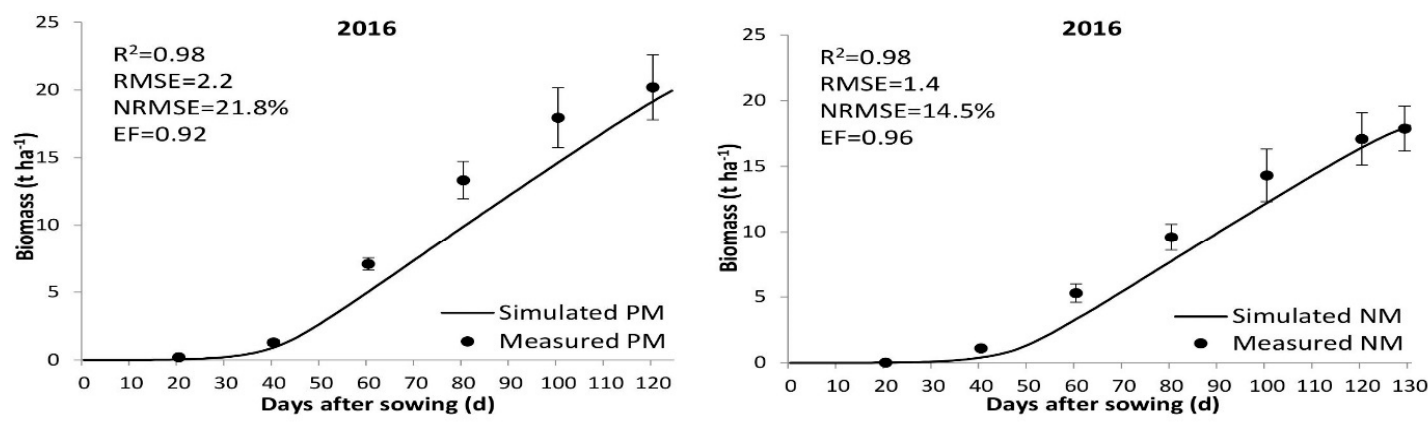

(b)
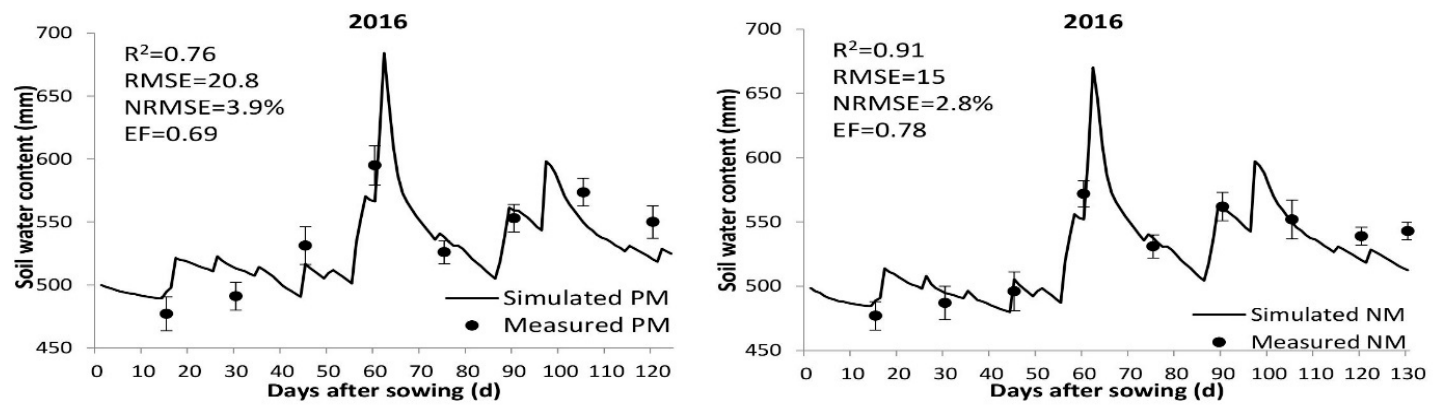

(c)

Figure 2. Calibration results showing comparisons between the simulated and measured (a) canopy cover; (b) biomass accumlation; and, (c) soil water content of foxtail millet for plastic film mulching (PM)-left, and no mulching (NM)-right, treatments in 2016 crop season.

Figure 2 and Table 4 reveal that the model accurately simulated the aboveground biomass accumulation for both PM and NM, with a low RMSE and NRMSE, a high $\mathrm{R}^{2}$ and EF, and small deviations ranging from $1.1 \%$ to $-2.8 \%$. However, the model tended to underestimate the biomass accumulation in the middle of the growth season. NM also had a more favorable simulation performance when compared with PM based on these statistical values.

Table 4. Calibration results of biomass, yield, crop evapotranspiration (ETc) and water user efficiency (WUE) for plastic film mulching (PM) and no mulching (NM) in 2016.

\begin{tabular}{ccccccc}
\hline \multirow{2}{*}{ Variables } & \multicolumn{3}{c}{ PM } & \multicolumn{3}{c}{ NM } \\
\cline { 2 - 7 } & Measured & Simulated & Deviation (\%) & Measured & Simulated & Deviation (\%) \\
\hline Biomass $\left(\mathrm{t} \cdot \mathrm{ha}^{-1}\right)$ & 20.532 & 19.954 & -2.8 & 17.913 & 18.101 & 1.1 \\
Yield $\left(\mathrm{t} \cdot \mathrm{ha}^{-1}\right)$ & 9.969 & 9.635 & -3.4 & 8.451 & 8.639 & 2.2 \\
ETc $(\mathrm{mm})$ & 328 & 295 & -10.0 & 339 & 324 & -4.5 \\
WUE $\left(\mathrm{kg} \cdot \mathrm{m}^{-3}\right)$ & 3.04 & 3.26 & 7.2 & 2.49 & 2.67 & 7.2 \\
\hline
\end{tabular}


The simulation of SWC generally achieved acceptable performance for both PM and NM in 2016 (Figure 2). However, SWC was slightly underestimated in the late growth season for both PM and NM. Apparently, the simulations of CC and biomass were more accurate than that of SWC, according to the statistical data (Figure 2). The simulation performance of NM was also more favorable than that of PM.

The model successfully predicted the yield for both treatments in 2016, with small deviations that were ranging from $2.2 \%$ to $-3.4 \%$. Fair predictions were also found in the results of ETc and WUE with deviations ranging from $-4.5 \%$ to $-10.0 \%$, and the deviations between the measured and simulated data were higher than those of the yield. NM also achieved a smaller deviation than PM for the simulation in these crop growth and water use indicators (Table 4).

\subsection{Model Validation}

\subsubsection{Canopy Cover Development}

The AquaCrop model was validated using the calibrated crop parameters. The model favorably simulated CC development in 2015 and 2017 (Figure 3) for both PM and NM. However, CC was underestimated in the early and late growth seasons for both PM and NM in 2015 and 2017. In general, the simulation of CC in 2017 demonstrated a stronger agreement between the simulated and measured data - with a higher R2 and EF and lower RMSE and NRMSE-than that of 2015 for all of the treatments. In addition, The CC simulation of PM $\left(R^{2}=0.98, \mathrm{RMSE}=5.2, \mathrm{NRMSE}=8.2 \%, \mathrm{EF}=0.98\right)$ performed better than NM $\left(R^{2}=0.97, \mathrm{RMSE}=6.7, \mathrm{NRMSE}=9.6 \%, \mathrm{EF}=0.96\right)$ in 2017. However, no such result was found in the CC simulation between PM and NM in 2015.

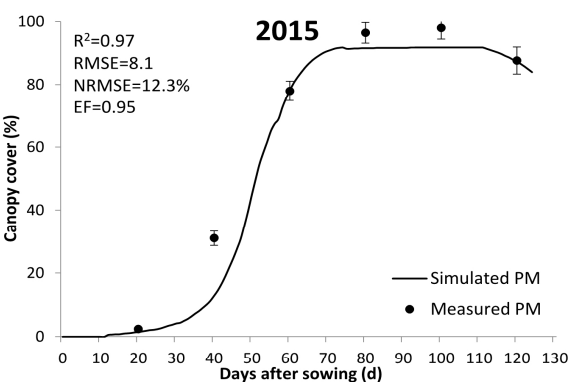

(a)

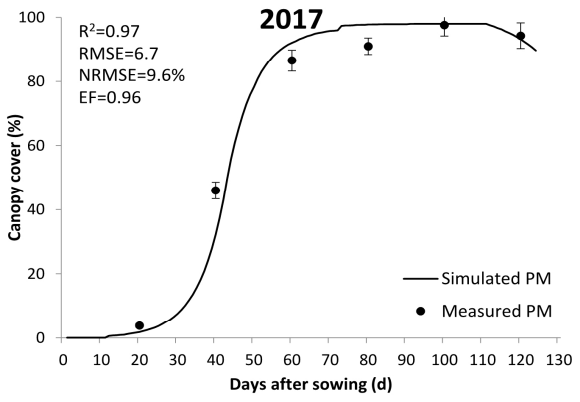

(c)

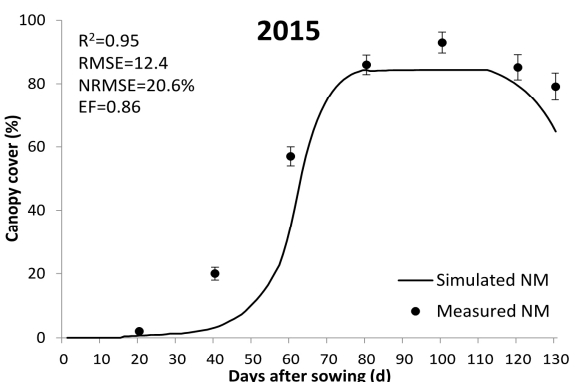

(b)

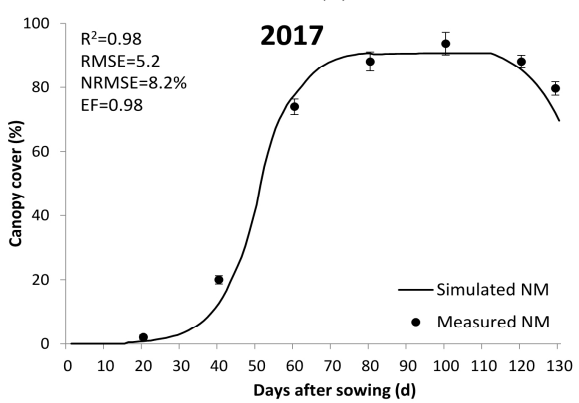

(d)

Figure 3. Validation results showing comparisons between simulated and measured canopy cover development for plastic film mulching (PM)-left, and no mulching (NM)-right, in 2015 and 2017 crop season. (a) PM treatment in 2015 (b) NM treatment in 2015 (c) PM treatment in 2017 (d) NM treatment in 2017.

\subsubsection{Biomass Accumulation and Yield}

The validation results of biomass accumulation indicated that the prediction of biomass for all the treatments were accurate both in 2015 and 2017 (Figure 4 and Table 5). Similar to the results in 2016 (calibration year), the model also slightly underestimated the biomass accumulation in the middle of growth season in both two years. Similar to the prediction result of CC, the agreement between the 
simulated and measured data of biomass in 2017 was more favorable than the agreement in 2015 for both of the treatments. The results showed that the performance of NM simulation was preferable to that of PM in 2017, while there were no similar results between PM and NM in 2015. The simulated yield of foxtail millet slightly differed from the measured values by $-2.9 \%$ for PM and $-2.8 \%$ for NM in 2017 (Table 5), which indicated that the model excellently predicted yield and the performance of NM was preferable to that of PM. However, no analogous yield simulation results were found between PM and NM in 2015.

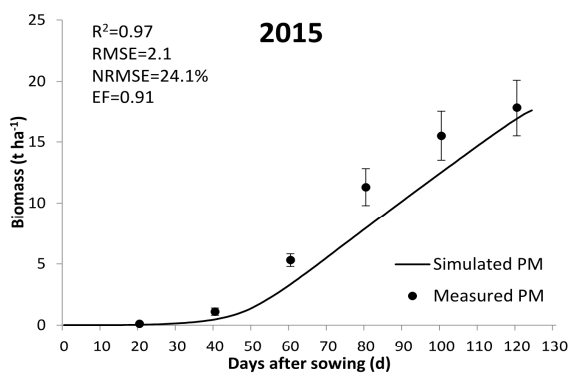

(a)

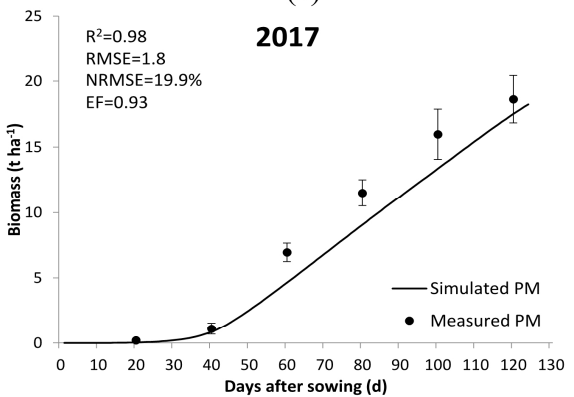

(c)

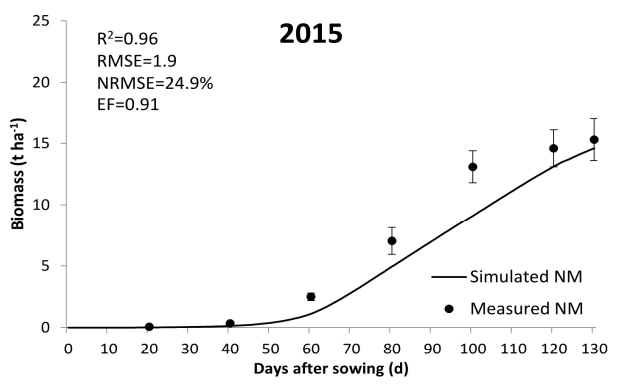

(b)

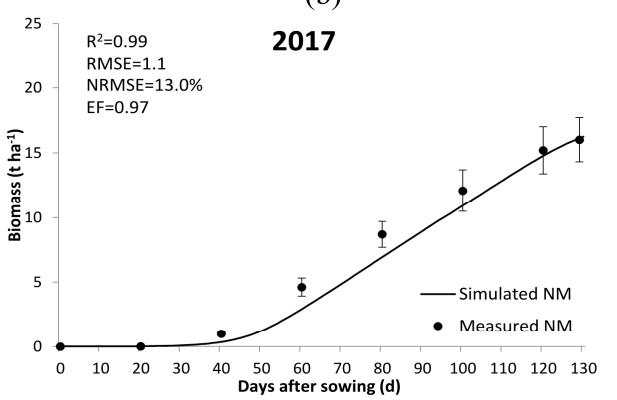

(d)

Figure 4. Validation results showing comparison between simulated and measured biomass accumulation for plastic film mulching (PM)-left, and no mulching (NM)-right, in 2015 and 2017 crop season. (a) PM treatment in 2015 (b) NM treatment in 2015 (c) PM treatment in 2017 (d) NM treatment in 2017.

Table 5. Validation results of biomass, yield, crop evapotranspiration (ETc) and water user efficiency (WUE) for plastic film mulching (PM) and no mulching (NM) in 2015 and 2017.

\begin{tabular}{|c|c|c|c|c|c|c|}
\hline \multirow{3}{*}{ Variables } & \multicolumn{6}{|c|}{2015} \\
\hline & \multicolumn{3}{|c|}{ PM } & \multicolumn{3}{|c|}{ NM } \\
\hline & Measured & Simulated & Deviation (\%) & Measured & Simulated & Deviation (\%) \\
\hline Biomass $\left(\mathrm{t} \cdot \mathrm{ha}^{-1}\right)$ & 18.751 & 17.580 & -6.3 & 15.311 & 14.599 & -4.7 \\
\hline Yield $\left(\mathrm{t} \cdot \mathrm{h} \mathrm{a}^{-1}\right)$ & 9.196 & 8.860 & -3.7 & 7.143 & 6.725 & -5.9 \\
\hline $\operatorname{ETc}(\mathrm{mm})$ & 333 & 284 & -14.8 & 339 & 281 & -17.1 \\
\hline \multirow[t]{4}{*}{ WUE $\left(\mathrm{kg} \cdot \mathrm{m}^{-3}\right)$} & 2.76 & 3.12 & 13.0 & 2.11 & 2.39 & 13.3 \\
\hline & \multicolumn{6}{|c|}{2017} \\
\hline & \multicolumn{3}{|c|}{ PM } & \multicolumn{3}{|c|}{ NM } \\
\hline & Measured & Simulated & Deviation (\%) & Measured & Simulated & Deviation (\%) \\
\hline Biomass $\left(\mathrm{t} \cdot \mathrm{ha}^{-1}\right)$ & 18.93 & 18.243 & -3.6 & 16.653 & 16.246 & 2.4 \\
\hline Yield $\left(\mathrm{t} \cdot \mathrm{ha} \mathrm{a}^{-1}\right)$ & 9.794 & 9.508 & -2.9 & 7.994 & 8.218 & -2.8 \\
\hline $\mathrm{ETc}(\mathrm{mm})$ & 327 & 294 & -9.9 & 313 & 283 & 9.7 \\
\hline WUE $\left(\mathrm{kg} \cdot \mathrm{m}^{-3}\right)$ & 3.00 & 3.24 & 8.0 & 2.55 & 2.69 & -5.5 \\
\hline
\end{tabular}




\subsubsection{Soil Water Content, Crop Evapotranspiration and Water Use Efficiency}

SWC was simulated with an acceptable result for both NM and PM in 2017 (Figure 5). The statistical indicators of NM revealed a higher $\mathrm{R}^{2}$ and EF, and a lower RMSE and NRMSE in 2017, relative to those of PM (Figure 5). The statistical indicators of SWC in 2015 demonstrated there was no strong correlation between the simulated and measured data for both PM and NM, which indicated that the model provided an unsatisfactory simulation for SWC in 2015. But, similar water extraction trends were noted between the measured and simulated data.

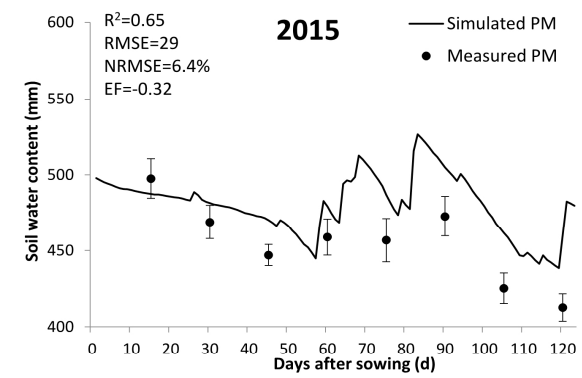

(a)

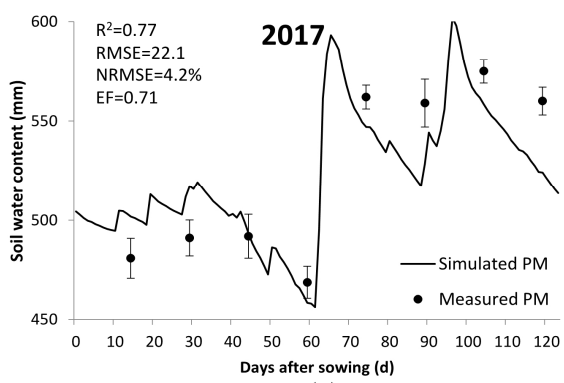

(c)

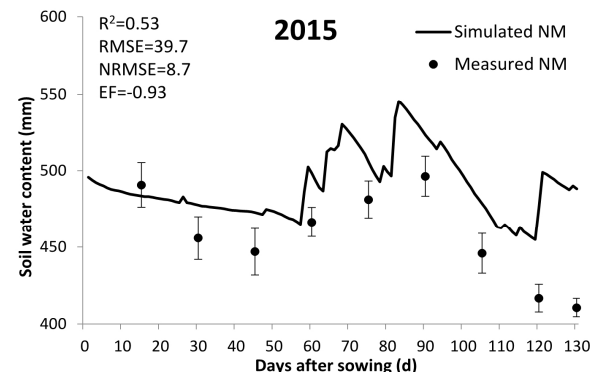

(b)

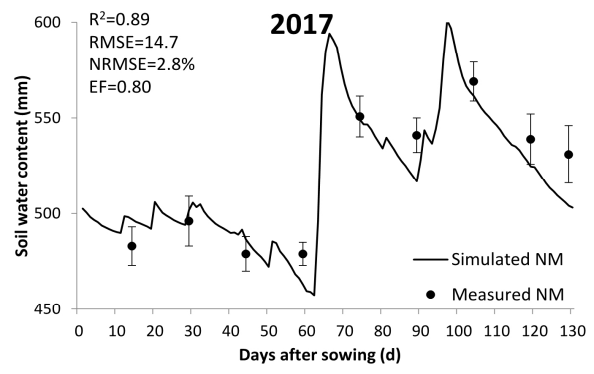

(d)

Figure 5. Validation results showing comparisons between simulated and measured soil water content for plastic film mulching (PM)-left, and no mulching (NM)-right, in 2015 and 2017 crop season. (a) PM treatment in 2015 (b) NM treatment in 2015 (c) PM treatment in 2017 (d) NM treatment in 2017.

The deviations of ETc and WUE were relatively higher than those of yield for both PM and NM in 2017 (Table 5), which ranged from $-5.5 \%$ to $-9.9 \%$, indicating that the simulation only provided acceptable performance. However, the results for ETc and WUE were unsatisfactory for both PM and NM in 2015 , with large deviations ranging from $13.0 \%$ to $-17.0 \%$. Overall, the simulation performance for foxtail millet yield and water use, namely ETc and WUE in 2017 was more favorable than that in 2015.

\section{Discussion}

The AquaCrop model achieved accurate predictions for CC development and biomass accumulation of foxtail millet for all treatments, as evidenced by the validation results from 2015 and 2017. The model also effectively simulated the yield of foxtail millet for all treatments in both 2015 and 2017, with small deviations ranging from $2.2 \%$ to $-5.9 \%$. These results of yield can mainly be attributed to the good simulation for biomass accumulation. Bello et al. [13] reported similar findings for CC development, biomass accumulation, and yield of pearl millet under different irrigations using AquaCrop. Liu et al. [35] used AquaCrop to simulated winter wheat under PM and NM conditions and achieved analogous results with this study, which included the $\mathrm{R}^{2}$ and NRMSE of CC simulation ranging from 0.86 to 0.99 and $2.9 \%$ to $11.9 \%$, respectively, and the $\mathrm{R}^{2}$ and NRMSE of biomass simulation ranging from 0.95 to 0.97 and $18.4 \%$ to $42.5 \%$, respectively. Some researchers have pointed out that AquaCrop slightly underestimated the CC and biomass in middle-late crop growth seasons, although the simulation obtained good results, such as with pearl millet [13] and maize [10]. Similar results were observed in all the treatments at present study. This could be because of the fact that AquaCrop simplifies the process of crop senescence, especially 
the process of CC decrease [36]. Furthermore, the biomass increases of the foxtail millet beyond 63 days after sowing might also have contributed to the underestimation [37]. Bello et al. [13] found similar underestimation of biomass in the simulation for pearl millet, and pointed out that this result was due to the biomass accumulation increased beyond 60 days after sowing.

Under different weather conditions, AquaCrop model simulated CC and biomass had varying performance degree. The agreement between the simulated and measured data in 2017 (normal year) was stronger than that for 2015 (dry year). As already mentioned, 2015 was drier and warmer than other years at the study location, which led to the severe water stress during the early growth season in 2015. This severe water stress was assumed to be one of the reasons for the relatively poor agreement that was demonstrated that year. Katerji et al. [38] tested the prediction of AquaCrop for corn and tomato under various water stress conditions, and wrote that the model performance was demonstrated to vary according to the level of plant water stress. Cosic et al. [5] simulated the growth of sweet pepper under different weather conditions and noted that "From the above, AquaCrop often fails to produce good results for yield if there is considerable water stress at any time during the growing season." Studies of maize [10,20] and groundnut [39] also have presented results that would seem to agree with this conclusion. The weather has different effects on the crop growth period, and this influence became more obvious on the crop planting with film mulching [40]. Under abnormal weather condition in 2015, the observed growth period of foxtail millet was obviously shorter than that of the calibration year (2016). This reduced the accuracy of simulation for CC and biomass in each growth stage using calendar mode. When compared with 2015, the difference between foxtail millet growth period in 2017 and that in the calibration year (2016) was smaller, so, this could be another reason why simulation in 2017 performed preferably to 2015. Additionally, the simulation of CC and biomass for NM generally outperformed than that of PM in 2017, which could be because AquaCrop only considers the change of soil evaporation under PM condition [32], leading to the effect of soil temperature change on crop growth and soil microorganisms being ignored in the simulation. However, this result was not observed in 2015. PM obtained markedly greater yields and biomass than NM under water stress conditions in 2015, in this case, it was clear that PM played a crucial role in mitigating the adverse impact of drought and high temperatures [5].

In general, the simulation performance of SWC progression for foxtail millet was acceptable in 2017 for all of the treatments, but it was unsatisfactory in 2015 for both treatments. No consistent conclusion could be derived from the literature regarding the results of simulating SWC using AquaCrop. Andarzian et al. [11] reported that the model obtained a good result in simulating SWC for different irrigation regimes in Iran. Wang et al. [8] noted analogous findings for winter wheat in northern China. In the study by Horemans et al. [41], the AquaCrop model showed good simulation performance for the daily soil water content for a short-rotation coppice application in Belgium. However, the study from Paredes et al. [12] showed that AquaCrop gave a bias in the estimation of soil water content for simulating soybeans, with a tendency for over-estimation during the first half of the season and under-estimation during the other half. Iqbal et al. [42] proposed that there was an analogous water-use trend, but there were also certain differences between simulated and measured SWC. Cosic et al. [5] simulated pepper growth using AquaCrop and observed no strong correlation between the simulated and measured data of SWC under both PM and NM conditions. In the present study, the accuracy of SWC prediction for both PM and NM were improved, which may be due to the use of an effective sampling method (seven soil layers) for SWC and a more precise soil sampling depth for foxtail millet rooting $(1.6 \mathrm{~m})$. These methods both reduced the sampling errors, so this study showed an acceptable result for SWC when compared with those unsatisfactory results reported by Cosic et al. [5]. The simulation performance of CC development and biomass accumulation will greatly influence the simulation of SWC progression [32]. Better predictions for CC and biomass in 2017 could be one reason for the differences of SWC simulation between 2015 and 2017.

AquaCrop was able to predict ETc and WUE for all treatments in 2017, with acceptable deviations ranging from $-4.5 \%$ to $-10.0 \%$. However, larger deviations were noted under severe water stress 
in 2015 for ETc (deviations > 14.8\%), which could be attributed to the poor simulation of SWC in 2015. This could be because the calculation of ETC is closely related to the simulation of SWC in AquaCrop [32]. Due to the large deviation of ETc, the simulation results for WUE in 2015 were unsatisfactory. In the study of Katerji et al. [38] using AquaCrop to simulate maize, the differences among observed and simulated seasonal evapotranspiration became unacceptable in the severely stressed treatments, and the linear regression between the observed and simulated values of WUE was unsatisfactory. Bello et al. [13] also reported similar results in predicting the SWC and cumulative ETc of pearl millet. The large deviations that were observed from this study revealed that the model requires further improvement in estimating WUE, which is mainly based on evapotranspiration simulation. Deviations between the simulated and actual data of yield, ETc, and WUE in 2017 were generally smaller than those values in 2015. As discussed above in CC and biomass simulation, the model performance declined, as there was severe water stress during crop season, as well as the difference of growth period between 2015 and 2017 all could be contributed to this case. Additionally, the simulation for NM had smaller deviations than that for PM in terms of yield, ETc, and WUE in the normal year (2017). Analogous simulation results were also found in the study of Liu et al. [35]. This, as previously mentioned, could due to the insufficient design of mulches part in AquaCrop, as well as the growth period of PM in 2017 was different from that in calibration year (2016). However, the simulation differences between PM and NM in 2017 were not found under water stress conditions in 2015. This might be because PM mitigated the adverse effect of the drought stress in 2015; consequently, the defect of model in simulating crop growth under severe water stress condition was weakened. Therefore, the simulation deviations of PM were reduced. From the above, there is room for improving the simulation performance of AquaCrop under severe drought stress and film mulching conditions.

\section{Conclusions}

The AquaCrop model was calibrated and validated for the canopy cover development, biomass accumulation, SWC progression, yield, ETc, and WUE of foxtail millet grown with PM and NM under different weather conditions. The results of the present study indicated that the model can predict the canopy cover development, biomass accumulation, and yield with a high degree of accuracy for both PM and NM in normal and dry years. It also simulated the SWC progression, ETc, and WUE with an acceptable degree for all treatments in normal year. However, the model performed unsatisfactorily for SWC progression, ETc, and WUE under severe drought stress condition. In general, AquaCrop can be used to predict growth and water use of foxtail millet under film mulching and no mulching conditions in rain-fed area when there is no severe drought stress. Additionally, in the normal year with no water stress, the simulation performance of AquaCrop was better under the NM than under the PM treatment.

Author Contributions: X.-Y.M. and P.-Y.G. conceived and designed the experiments; D.-X.G. and X.-Y.Y. performed the experiments; D.-X.G., C.-F.C. and X.-G.X. analyzed the data; X.-Y.M. contributed reagents/materials/analysis tools; D.-X.G. wrote the paper; and X.-Y.M. revised the paper.

Funding: This work was financially supported by National Natural Science Foundation of China (No. 51279167), Special Fund for Agro-scientific Research in the Public Interest (No. 201503124), National Millet and Sorghum Industry Technical System Project (CARS-06-13.5-A28), the Program for the Top Young Innovative Talents of Shanxi Agricultural University (TYIT201406) and Shanxi Academy of Agricultural Sciences Crop Innovation Institute Youth Innovation Fund (2Q1703).

Conflicts of Interest: The authors declare no conflict of interest.

\section{Abbreviations}

$\begin{array}{ll}\text { PM } & \text { plastic film mulching } \\ \text { NM } & \text { no mulching } \\ \text { SWC } & \text { soil water content } \\ \text { CC } & \text { canopy cover } \\ \text { ETc } & \text { evapotranspiration } \\ \text { WUE } & \text { water use efficiency }\end{array}$




\section{References}

1. Kasirajan, S.; Ngouajio, M. Polyethylene and biodegradable mulches for agricultural applications: A review. Agron. Sustain. Dev. 2012, 32, 501-529. [CrossRef]

2. Zhang, S.; Sadras, V.; Chen, X.; Zhang, F. Water use efficiency of dryland wheat in the loess plateau in response to soil and crop management. Field Crop. Res. 2013, 151, 9-18. [CrossRef]

3. Zhou, L.-M.; Li, F.-M.; Jin, S.-L.; Song, Y. How two ridges and the furrow mulched with plastic film affect soil water, soil temperature and yield of maize on the semiarid loess plateau of China. Field Crop. Res. 2009, 113, 41-47. [CrossRef]

4. Zhao, X.; Othmanli, H.; Schiller, T.; Zhao, C.; Sheng, Y.; Zia, S.; Mueller, J.; Stahr, K. Water use efficiency in saline soils under cotton cultivation in the Tarim river basin. Water 2015, 7, 3103-3122. [CrossRef]

5. Cosic, M.; Stricevic, R.; Djurovic, N.; Moravcevic, D.; Pavlovic, M.; Todorovic, M. Predicting biomass and yield of sweet pepper grown with and without plastic film mulching under different water supply and weather conditions. Agric. Water Manag. 2017, 188, 91-100. [CrossRef]

6. Steduto, P.; Hsiao, T.C.; Raes, D.; Fereres, E. AquaCrop-the FAO crop model to simulate yield response to water: I. Concepts and underlying principles. Agron. J. 2009, 101, 426-437. [CrossRef]

7. Todorovic, M.; Albrizio, R.; Zivotic, L.; Saab, M.-T.A.; Stockle, C.; Steduto, P. Assessment of AquaCrop, cropsyst, and wofost models in the simulation of sunflower growth under different water regimes. Agron. J. 2009, 101, 509-521. [CrossRef]

8. Wang, X.X.; Wang, Q.J.; Fan, J.; Fu, Q.P. Evaluation of the aqua crop model for simulating the impact of water deficits and different irrigation regimes on the biomass and yield of winter wheat grown on China's loess plateau. Agric. Water Manag. 2013, 129, 95-104.

9. Nyakudya, I.W.; Stroosnijder, L. Effect of rooting depth, plant density and planting date on maize (Zea mays L.) yield and water use efficiency in semi-arid Zimbabwe: Modelling with AquaCrop. Agric. Water Manag. 2014, 146, 280-296. [CrossRef]

10. Hsiao, T.C.; Heng, L.; Steduto, P.; Rojas-Lara, B.; Raes, D.; Fereres, E. AquaCrop-the FAO crop model to simulate yield response to water: III. Parameterization and testing for maize. Agron. J. 2009, 101, 448-459. [CrossRef]

11. Andarzian, B.; Bannayan, M.; Steduto, P.; Mazraeh, H.; Barati, M.E.; Barati, M.A.; Rahnama, A. Validation and testing of the AquaCrop model under full and deficit irrigated wheat production in Iran. Agric. Water Manag. 2011, 100, 1-8. [CrossRef]

12. Paredes, P.; Wei, Z.; Liu, Y.; Xu, D.; Xin, Y.; Zhang, B.; Pereira, L.S. Performance assessment of the FAO AquaCrop model for soil water, soil evaporation, biomass and yield of soybeans in north china plain. Agric. Water Manag. 2015, 152, 57-71. [CrossRef]

13. Bello, Z.A.; Walker, S. Calibration and validation of AquaCrop for pearl millet (Pennisetum glaucum). Crop Pasture Sci. 2016, 67, 948. [CrossRef]

14. Malik, A.; Shakir, A.S.; Ajmal, M.; Khan, M.J.; Khan, T.A. Assessment of AquaCrop model in simulating sugar beet canopy cover, biomass and root yield under different irrigation and field management practices in semi-arid regions of Pakistan. Water Resour. Manag. 2017, 31, 4275-4292. [CrossRef]

15. Ran, H.; Kang, S.; Li, F.; Tong, L.; Ding, R.; Du, T.; Li, S.; Zhang, X. Performance of AquaCrop and Simdualkc models in evapotranspiration partitioning on full and deficit irrigated maize for seed production under plastic film-mulch in an arid region of China. Agric. Syst. 2017, 151, 20-32. [CrossRef]

16. D’Ippoliti, D.; Michelozzi, P.; Marino, C.; de’Donato, F.; Menne, B.; Katsouyanni, K.; Kirchmayer, U.; Analitis, A.; Medina-Ramon, M.; Paldy, A.; et al. The impact of heat waves on mortality in 9 European cities: Results from the Euroheat project. Environ. Health 2010, 9, 37. [CrossRef] [PubMed]

17. Valipour, M.; Sefidkouhi, M.A.G.; Raeini-Sarjaz, M. Selecting the best model to estimate potential evapotranspiration with respect to climate change and magnitudes of extreme events. Agric. Water Manag. 2017, 180, 50-60. [CrossRef]

18. Nouri, M.; Homaee, M.; Bannayan, M.; Hoogenboom, G. Towards modeling soil texture-specific sensitivity of wheat yield and water balance to climatic changes. Agric. Water Manag. 2016, 177, 248-263. [CrossRef] 
19. Bird, N.D.; Benabdallah, S.; Gouda, N.; Hummel, F.; Koeberl, J.; Jeunesse, L.I.; Meyer, S.; Prettenthaler, F.; Soddu, A.; Gallasch, W.G. Modelling climate change impacts on and adaptation strategies for agriculture in Sardinia and Tunisiausing AquaCrop and value-at-risk. Sci. Total Environ. 2016, 543, 1019-1027. [CrossRef] [PubMed]

20. Greaves, G.; Wang, Y.M. Assessment of FAO AquaCrop model for simulating maize growth and productivity under deficit irrigation in a tropical environment. Water 2016, 8, 557. [CrossRef]

21. Fei, L.; Meng, L.; Yu, Z.; Mei, N.C.; Yan, X.X.; Jia, S.S.; Li, R.X.; Guo, L.S. Development trends of China's foxtail millet and broomcorn millet industry in 2016. Agric. Outlook 2016, 10, 39-42. (In Chinese)

22. Dong, B.D.; Liu, M.Y.; Jiang, J.W.; Shi, C.H.; Wang, X.M.; Qiao, Y.Z.; Liu, Y.Y.; Zhao, Z.H.; Ii, D.X.; Si, F.Y. Growth, grain yield, and water use efficiency of rain-fed spring hybrid millet (Setaria italica) in plastic-mulched and unmulched fields. Agric. Water Manag. 2014, 143, 93-101. [CrossRef]

23. Singh, P.; Boote, K.J.; Kadiyala, M.D.M.; Nedumaran, S.; Gupta, S.K.; Srinivas, K.; Bantilan, M.C.S. An assessment of yield gains under climate change due to genetic modification of pearl millet. Sci. Total Environ. 2017, 601-602, 1226-1237. [CrossRef] [PubMed]

24. Tao, L.W.; Ma, H.; Ge, F.L. Analysis on the characteristics of precipitation in Shannxi province. Shanxi Meteorol. 2000, 2, 6-9.

25. Araya, A.; Keesstra, S.D.; Stroosnijder, L. Simulating yield response to water of teff (Eragrostis tef) with FAO's AquaCrop model. Field Crop. Res. 2010, 117, 265. [CrossRef]

26. United States Department of Agriculture (USDA). Keys to Soil Taxonomy, 11th ed.; Books Express Publishing: Berkshire, UK, 2010.

27. Liu, Y.Z.; Zhang, J.Y. Shan xi Soil; Science Press: Marrickville, Australia, 1992.

28. Jia, M.Y. Water resources development and utilization status and countermeasures for sustainable development in Taigu County. Ground Water 2013, 35, 36-37.

29. Raes, D.; Gaelen, H.V. AquaCrop Training Handbooks-Book II Running AquaCrop; Food and Agriculture Organization of the United Nations: Rome, Italy, 2016.

30. Farahani, H.; Izzi, G.; Steduto, P.; Oweis, T. Parameterization and evaluation of the AquaCrop model for full and deficit irrigated cotton. Agron. J. 2009, 101, 469-476. [CrossRef]

31. Yang, N.; Sun, Z.; Zheng, M.; Feng, L.; Zhang, L.; Bai, W.; Xiang, W. Performance assessment of combining AquaCrop model with recalculating air temperature of straw-mulching maize for estimating evapo-transpiration and yield. Int. J. Agric. Biol. 2017, 19, 1156-1164. [CrossRef]

32. Raes, D.; Steduto, P.; Hsiao, C.T.; Fereres, E. Reference Manual, Chapter 3-AquaCrop, Version 6.0; Food and Agriculture Organization of the United Nations: Rome, Italy, 2018.

33. Moriasi, D.N.; Arnold, J.G.; Van Liew, M.W.; Bingner, R.L.; Harmel, R.D.; Veith, T.L. Model evaluation guidelines for systematic quantification of accuracy in watershed simulations. Trans. Asabe 2007, 50, 885-900. [CrossRef]

34. Bannayan, M.; Hoogenboom, G. Using pattern recognition for estimating cultivar coefficients of a crop simulation model. Field Crop. Res. 2009, 111, 290-302. [CrossRef]

35. Liu, X.; Ding, D.Y.; Zhang, H.J.; Chu, X.S.; Yu, K.; Feng, H. Evaluation analysis of AquaCrop model in modeling winter wheat growing development and soil moisture under plastic mulching. Sci. Agric. Sin. 2017, 50, 1838-1851. (In Chinese)

36. Ahmadi, S.H.; Mosallaeepour, E.; Kamgar-Haghighi, A.A.; Sepaskhah, A.R. Modeling maize yield and soil water content with AquaCrop under full and deficit irrigation managements. Water Resour. Manag. 2015, 29, 1-17. [CrossRef]

37. Zeleke, K.T.; Luckett, D.; Cowley, R. Calibration and testing of the FAO AquaCrop model for canola. Agron. J. 2011, 103, 1610-1618. [CrossRef]

38. Katerji, N.; Campi, P.; Mastrorilli, M. Productivity, evapotranspiration, and water use efficiency of corn and tomato crops simulated by AquaCrop under contrasting water stress conditions in the Mediterranean region. Agric. Water Manag. 2013, 130, 14-26. [CrossRef]

39. Karunaratne, A.S.; Azamali, S.N.; Izzi, G.; Steduto, P. Calibration and validation of fao-aquacrop model for irrigated and water deficient bambara groundnut. Exp. Agric. 2011, 47, 509-527. [CrossRef]

40. Siczek, A.; Horn, R.; Lipiec, J.; Usowicz, B.; Lukowski, M. Effects of soil deformation and surface mulching on soil physical properties and soybean response related to weather conditions. Soil Tillage Res. 2015, 153, 175-184. [CrossRef] 
41. Horemans, J.A.; Gaelen, H.V.; Raes, D.; Zenone, T.; Ceulemans, R. Can the agricultural aquacrop model simulate water use and yield of a poplar short-rotation coppice? Glob. Chang. Biol. Bioenergy 2017, 9, 1151-1164. [CrossRef] [PubMed]

42. Iqbal, M.A.; Shen, Y.; Stricevic, R.; Pei, H.; Sun, H.; Amiri, E.; Penas, A.; Rio, S.D. Evaluation of the fao aquacrop model for winter wheat on the north china plain under deficit irrigation from field experiment to regional yield simulation. Agric. Water Manag. 2014, 135, 61-72. [CrossRef] 